\title{
MOBILE DEVICE SUPPORTED ONLINE EXAMINATION SYSTEM APPROPRIATE TO DISTANCE LEARNING
}

\author{
Ozgun Bursalioglu', Murat Luy ${ }^{2}$, Volkan Ates ${ }^{3}$, Atilla Erguzen ${ }^{4}$ \\ ${ }^{1}$ Ms., Kirikkale University, TURKEY, ozgunb@gmail.com \\ ${ }^{2}$ Asst. Prof. Dr., Kirikkale University, TURKEY, muratluy@yahoo.com \\ ${ }^{3}$ PhD., Kirikkale University, TURKEY, volkanfire@hotmail.com \\ ${ }^{4}$ Asst. Prof. Kirikkale University, TURKEY, aerguzen@hotmail.com
}

\begin{abstract}
In modern life, information technology has entered into almost every area of people's daily lives and become an important and undeniable part of business, educational and personal life. Thus, technological innovations that became widespread in political, economic, institutional and cultural fields are also being widespread in the educational field. Until recently the existing technical shortcomings, the problems of real-time operation of systems, the difficulty and expensiveness of providing the necessary system were making it almost impossible to apply these technological innovations to education and examination systems.
\end{abstract}

At the present day, studying in various schools and courses in order to fulfill the needs of life, improve ourselves and our lives is essential for us. Eventually, exams are administered in various ways to measure people's level of education, practical and theoretical knowledge and abilities. In the traditional education system, trainers and learners should adapt to each other in terms of time and venue and they have to fit in the same place at the same time. This particularly leaves learners in the lurch in their personal life and force them education priority scheduling. Despite this situation, it makes impossible to receive training for working people and people with disabilities and also makes it difficult for learners to develop themselves.

Web-based learning and online examination systems are able to deliver the required web content to the user on all devices with web browsers such as desktop computers, tablet computers, and even some televisions. Because of high sales and maintenance fees, deficiency of existing properties on fulfilling the needs of the institution, inability of adding new features of commercial systems make it disadvantageous to use them. In the open source systems, obligations for the institution to pay to the developer company for eliminating the problems that may occur in using process, insufficiency of technical documentation and difficulties on developing software for these reasons, these systems are also not preferred. The goal of our work is to develop an institution-specific, user-friendly web-based online examination system that minimizes operating costs, allows the institution to add new features easily by expert teams, meets the needs of the institution, integrates the current learning management system. We have developed our application in accordance with the requirements of the Distance Learning Center of Kırıkkale University using the contemporary software (Asp.NET MVC5, Angular JS, Bootstrap, Microsoft SQL Server 2014) techniques.

Keywords: Online Examination, Distance Learning, Web-based Examination, Learning Management System. 


\section{INTRODUCTION}

The purpose of the measurement and evaluation activities carried out to evaluate the success of students is not only to measure their success, at the same time it allows to review and improve the provided education and used measuring tools to enhance their learning method according to the obtained results. For developing the learning method, in addition to the traditional measurement and assessment methods, a number of different alternatives of assessment instruments are used [8]. Traditional evaluation methods consist of examinations that are done in the real environment using paper, pencil and questions with multiple choices, true / false answer, short-answer and open-ended questions. Examples of alternative training methods are performance evaluation and problem-based learning methods. The rapid development of information technology has led online training models and online examination systems, which presents the significant part of learning systems, place an important role in the field of education alternatively to these training and examination models. Online examination system is an effective method that allows distributing the exam content to users using the internet, easily analyze and report the scores, measure and evaluate the students' knowledge level. In addition, these systems are defined as a system that provides ability to teachers and lecturers to apply exams to students concurrently and asynchronously with creating a virtual test space. However, traditional methods are applied as the preferred method for assessing the results of the online and offline exam results [9]. In this paper, we focused on web-based online examination system that satisfies the requirements of the exam, which are most important part of assessment and evaluation processes of education.

Online examination system, which we developed, unlike previous works, allows creating various test structures, utilizing various question environments and provides different types of questions when teachers make online quizzes. These features allow evaluating of students' knowledge from different perspectives.

The rest of the article is as follows: Section 2 presents the related work that was instrumental in the development of our work. Section 3 describes general information about web-based online examination systems. Section 4 presents general architecture of our web-based online examination system, user roles in the system and structure of generated database. Section 5 shows how to prepare questions, compose exams and exam applications and realization of these applications. Section 6 presents the conclusion of paper and the future works.

\section{RELATED WORK}

Nowadays, web-based online examination systems are considered as an important resource for university education system and worldwide important certification exams. Considering made studies about online examination systems until today, it is determined that the spent time in different examination environments by students and their performance, come out with different results according to exam types, variety of questions and the structure of the examination system. In the study presented in 2006 by Sampson [13], author argues that the usage of different types of questions in the exam system would affect the results favorably and it would be useful for evaluating the skills of individuals with limited literacy skills. In their works, Shen et al. [15] emphasizes the importance of adjustment and updating in accordance with feedback from students for the properly execution of online exams. Zhang [21] showed that it obtains rapid increase on number of students in online education and examination system. They associated the reason of this increasing with the time and space independence of study. In most of these studies, the theoretical models on test systems are supplied with the application approaches. The examination architecture developed by Jin and Ma [6] is solely based on students' and teachers' feedback and assistance. They emphasized the importance of received feedback in the realized reporting and analysis processes for the smooth running of the proper management examination results. Crisp and Ward [3] revealed the importance of online systems to capture a large number of feedback from students effectively. Aimin \& Jipeng [1] included intelligent approaches for making random choices through linear algorithms to the online examination system architecture in question selection and application preparing process. Bilayer examination system proposed by Mustakerov and Borissov [12] provides a crucial advantage on testing process thanks to its flexible adjustment approach. Furthermore, researchers defined that their improved system is appropriate to be used in formal or informal assessment processes. Online exam system architecture presented by Hang [5] contains automatic scoring, updatable question pool, flexible question design and system security features. Tugrul Tasci et al. [17] proposed architecture of intelligent agent-supported integrated online examination system. Yagcı Mustafa et al. [11] offered online examination system structure with multimedia support and updatable database formation. Some of the most important features of the examination system are value on data security and easy to use interface.

After reviewing all the important features and disadvantages of these studies, we improved following web- 
based online examination system. Our purpose is to develop reliable, practical and advantageous online examination system in terms of time and resources, also support distance education and ensure the application of the exams in an effective way.

\section{WEB-BASED ONLINE EXAMINATION SYSTEMS}

Web-based online examination systems are the most important and advanced representatives of the online exam, which takes an important place in education. Online examination systems use the web browsers to deliver data to users quickly and can be applied at anytime and anywhere that internet connection is available. Distribution of exam questions and tests in this way significantly reduce the time spent on the evaluation of exam and on additional expenses. These properties allow the implementation of surveillance and routing methods that are important parts of the evaluation of the students but ignored because of the long time spent. Furthermore, if this acquired time is spent to correction of detected problems in the education system, it will make an important contribution to the improvement of the teaching-learning process. One of the most important features of a web-based online examination system is its design that is proper to modern education and training needs [4]. Besides this, the elimination of existing restrictions in terms of time and space provides participating more students to education and exams [7,21]. Fig. 1 shows the general structure of web-based online examination systems.

Examinations are made by traditional methods cause too much loss of time and resources. In real world environments, preparation of questions, test and exam papers, distribution to students and the realization of the tests and exams are the most important operations. In the environment created by web-based online examination system, teachers just spend the time to create the questions, all other operations are performed by the system and will not cause any loss of time.

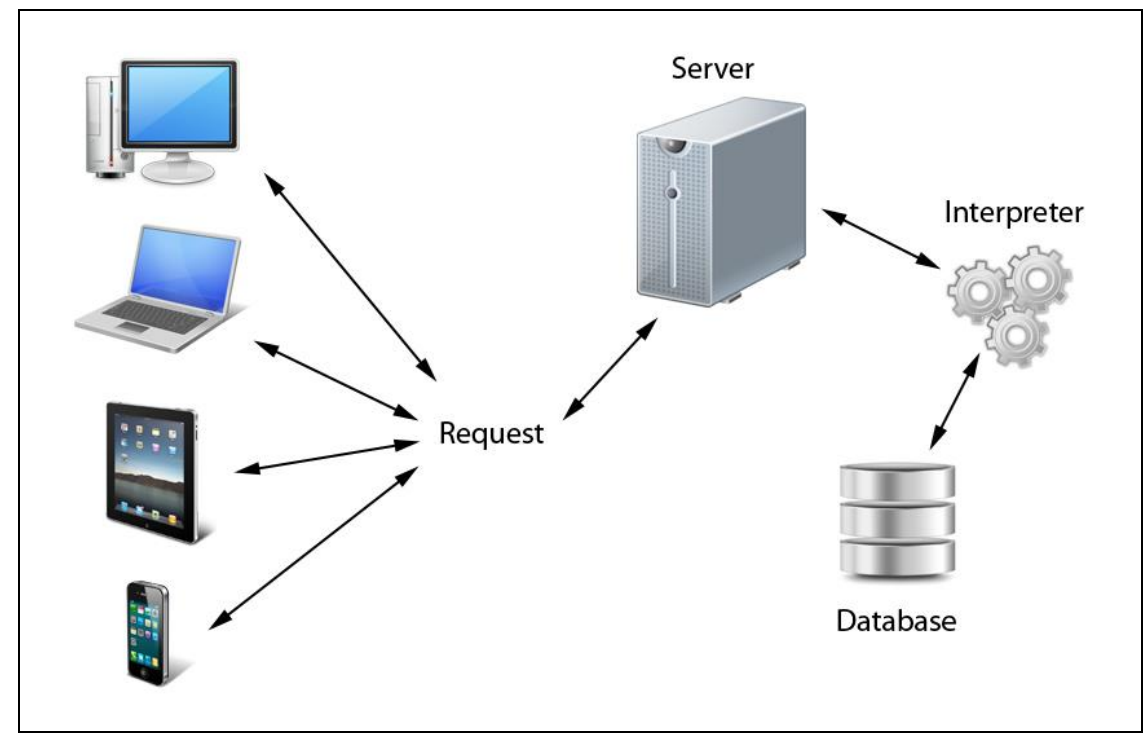

Fig 1. Working scheme of web based online examination system

This prevents the expenditure of questions resources and waste of time. In addition, these systems give flexibility to students in terms of time and usage of various question types increases the success of their results [19]. One of the most important reasons of preference of these systems is the significant reduction of spent costs for creation of exams and evaluation of results.

Web-based online examination system facilitates the creation and performance of examination process for the academic staff [20]. In these systems, question pools enrich more quickly and examination results are evaluated effectively. In addition, online examination systems significantly reduced measurement and evaluation errors conducted on student results. In previous online systems, it is observed that students have difficulty to adapt and concentrate to the examination environment and the students finish exams in longer time. We notice that when web-based online examination system compared with examination made by traditional methods, it has been proven that it enhance the examination standards in the field of education.

\section{GENERAL STRUCTURE OF THE DEVELOPED SYSTEM}

The developed web-based online examination system consists of three main parts. These are the database, 
server and clients parts. In this system, we used Microsoft Windows Server that commonly preferred by software developers. Microsoft Windows Server is an operation system that has stable working state and powerful technical support.

ASP.Net framework and C\# language are preferred for the general structure of the web-based online examination system. MVC architectural pattern, which is a vital property that is added to ASP.Net platform in recent years, is used to achieve more efficacious results. It is mainly formed of the model, view and controller parts. With this pattern which is preferred in large-scale projects, a modular structure is provided, system management is facilitated and new features can be easily added later if needed. The designed user interface is HTML based and supported by javascript based jQuery library. During the development of the software, AngularJS library, which works client-side, is used to provide flexibility. Thus, it has avoided the use of conventional low-performance user interface components of ASP.Net, and AngularJS supported HTML5 components that have high working performance are used. In the systems which are developed with conventional ASP.Net components, the server re-sends all of the web page content to the client each time the client make requests. Therefore, large amounts of data transfer are performed, which lowers the performance. However, in javascript-based structures, only the required data can be requested from the server and thus low data transfer can be achieved.

\subsection{Created Database}

Microsoft SQL Server is used in our system considering that it has high operating performance and a reliable structure as the database. MySQL and ORACLE databases can also be used to store data on this system. In the view of the ASP.Net is a product of same company with Microsoft SQL Server, we use Microsoft SQL Server as the database for the purpose of they can be more compatible with each other. The advantages of this database are stated below [16] :

- This database has a long operating time.

- Database tables have infinite row count that is limited by only hard drive capacity.

- It supports 32767 user connections simultaneously.

- There can be added over 2.000.000.000 tables.

- This database has a high operating performance and dependable in use.

- It supports multiple processors.

Relational table structure is used during preparing of database tables. This avoids the duplications of data. Besides, it reduces the workload during the development of the software, it lowers the use of system resources [10] and eliminates the logic errors. Apart from this, clients can connect to the web based online examination system by any web browser (Google Chrome, Internet Explorer, Mozilla Firefox, Safari, Opera) according to their needs.

\subsection{User Roles}

There are five types of users in the system : master, admin, question editor, teacher and student. System allows users to have multiple roles and be changed for any user later. All users use the same login page to enter the examination system. Then they will be met with dynamic menus and screens according to roles they have. The properties of the roles are stated below :

Master Role: This role established during the initial installation of the system and can be defined only for a single user. This user has all privileges on the system.

Admin Role: Users with this role can be created by the user in the master role. Also units and teachers which this user has authorization are defined by master user.

Question Editor Role: Question editors are users who prepare new questions to the digital question pool. Master or admin users have the authorization to define which question editor can prepare questions for which courses.

Teacher Role: Teachers set up tests with the questions from digital question pool and apply these tests as exam, short exam or practice test to students. Master or admin users define which teacher responsible of which courses.

Student Role: These users take the tests that teachers assigned them and answer questions, view scores and correct answers after application. They are also able to make feedbacks about assignments or 
questions to them.

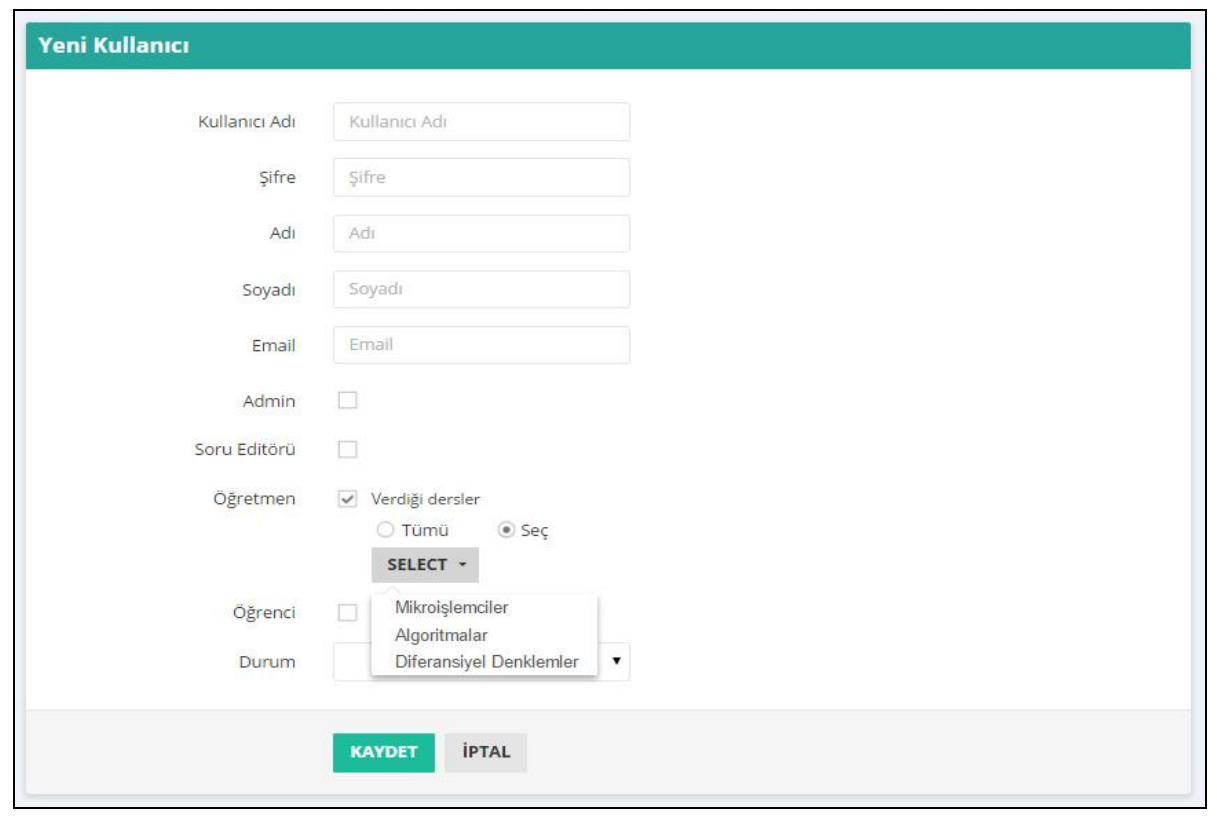

Fig 2. New user form

\section{EXAM}

\subsection{Creating Questions}

Users who have question editor role can create new questions with various types for the digital question pool in the system. If user hovers the "Yeni Soru" (New Question) option under the "Sorular" (Questions) menu, list of the question types will be displayed that each one opens related question preparation form. These question types are categorized by "coktan secmeli" (single selection), "coklu seçmeli" (multiple selection), "dogru/yanlis" (true/false), "siralama" (sorting), "kisa cevap" (short answer), "acik cevapli" (open ended) questions [14].

During the preparation of the questions except open ended type by the question editors, correct answer must be entered before saving it. Thus, after the exam finishes student answers can be automatically scored. On Table 1, supported question objects and types are compared for three different systems including our's.

\begin{tabular}{|l|c|c|c|}
\hline \multicolumn{1}{|c|}{ Property } & WizIQ & TAO & WTÇSS \\
\hline Single selection question type & Yes & Yes & Yes \\
\hline True/false question type & No & No & Yes \\
\hline Open ended question type & No & Yes & Yes \\
\hline Multiple selection question type & No & Yes & Yes \\
\hline Sorting question type & No & Yes & Yes \\
\hline Additional question types & No & Yes & No \\
\hline Question categorization & No & No & Yes \\
\hline Multimedia file support & No & Yes & Yes \\
\hline Supports images on choices & No & Yes & Yes \\
\hline Making questions inactive & No & No & Yes \\
\hline Question confirmation mechanism & No & No & Yes \\
\hline Question versioning & No & No & Yes \\
\hline
\end{tabular}

Table 1. Compare of question objects

The questions are divided into two parts, including question body and feedback area. There can be text 
and/or multimedia file in the question body. The multimedia file should be in .jpg, .png, .gif, .mp3, .mp4 formats. Feedback area is configured in order to selected type of question dynamically. Image file supported choices can be added for multiple choice questions. The course should be selected before saving the question to the system. In addition, one or more category tag can be added to make the question be easily found by teachers during the searching processes. New single selection type question form of our system is seen on Fig 3.

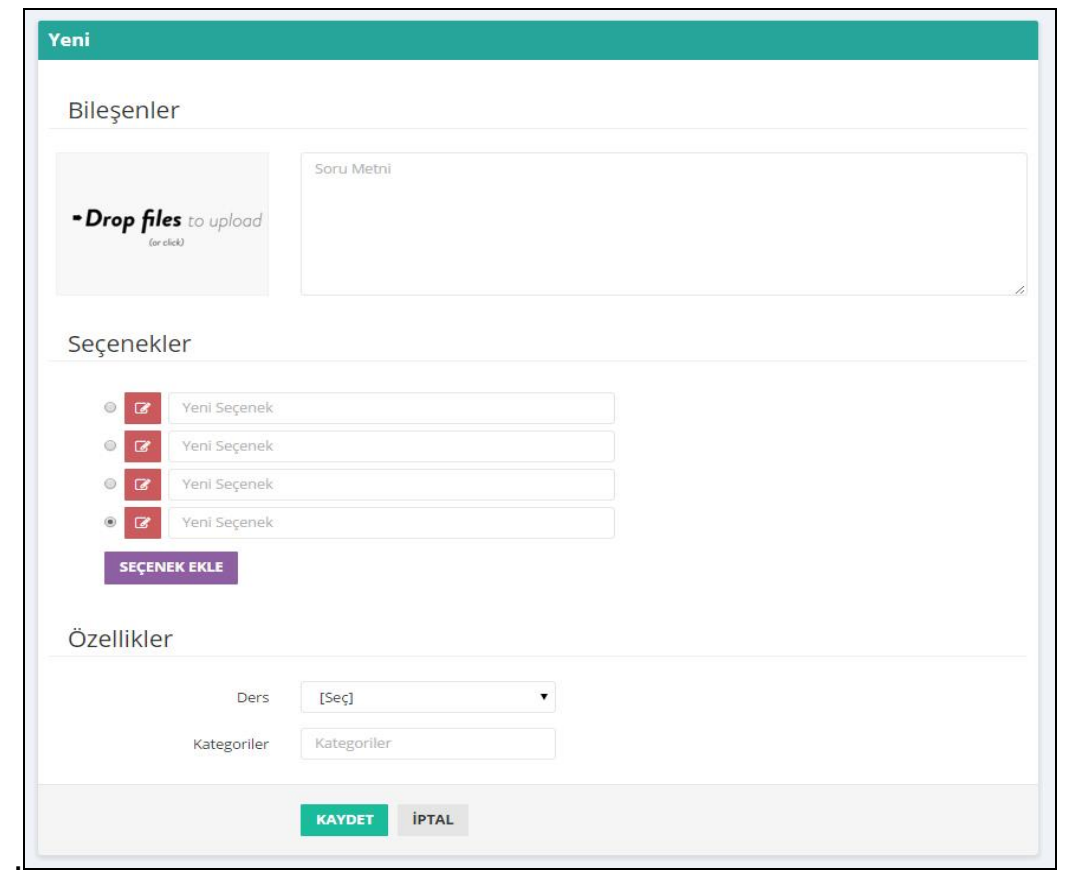

Fig 3. New single selection type question form

When a question edited by question editor, a new question data will be created on database with updated info and the old one will become inactive. In this way of versioning, if the old version of the question is used in an assignment before, affection of retroactive data will be avoided. In the new uses of the question, only the updated version will be available.

\subsection{Creating Tests And Assignments}

Teachers prepare tests for the courses they responsible for from the digital question pool. New test form panel is viewed by "Yeni" (New) option under "Testler" (Tests) from the main menu. There are two ways to add questions to newly created test. Single questions can be searched from question pool with the panel that opens with "Soru Ekle" (Add Question) button. Question type, author, editor, course and last update filters can be used to search and questions can be selected from the results list to add one by one questions. The other way of adding questions is to use the random questions panel that opens with "Rastgele" (Random) button. Teacher sets filters and question number according to the needs, then system will add random stated number of questions that correspond to filters. These two options can be used more than once in same test preparation. Point values and the order of the questions can be set by teacher. Test preparation form is shown on Fig 4.

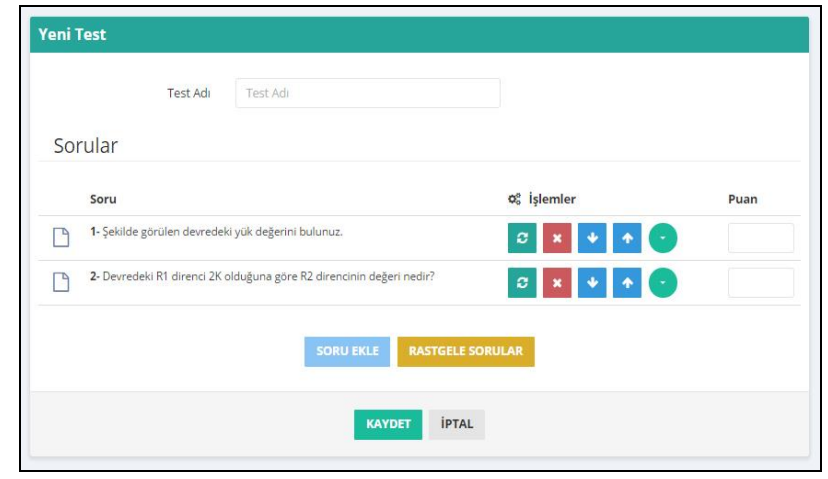

Fig 4. Test preparation form 
To assign one of the tests as an exam, quiz or practice test to students, "Uygula" (Assign) button can be used from the related row of tests list or from the test detail panel. First, assignment type should be selected from assignment panel. If "Sinav" (Exam) option selected, start time and duration info should be entered from fields that appeared. For the "Calisma Testi" (Practice Test) option, there is no need for time and duration info. If teacher prefers the system to automatically score the student answers at the end of the examination, "Otomatik Puanla" (Automatically Score) checkbox should be checked. The students to assign test are selected from "Uygulanacak Ogrenciler" (Students to Assign) panel. There can be selected a group of students who take same course, or a single student can be searched. "Olustur" (Create) button creates the assignments. The teacher can list his/her own assignments from "Uygulamalar" (Assignments) option under "Testler" (Tests) from main menu. Assignment management and reporting operations can be made from assignment detail panel. On quiz assignments, teacher should start and finish the session manually.

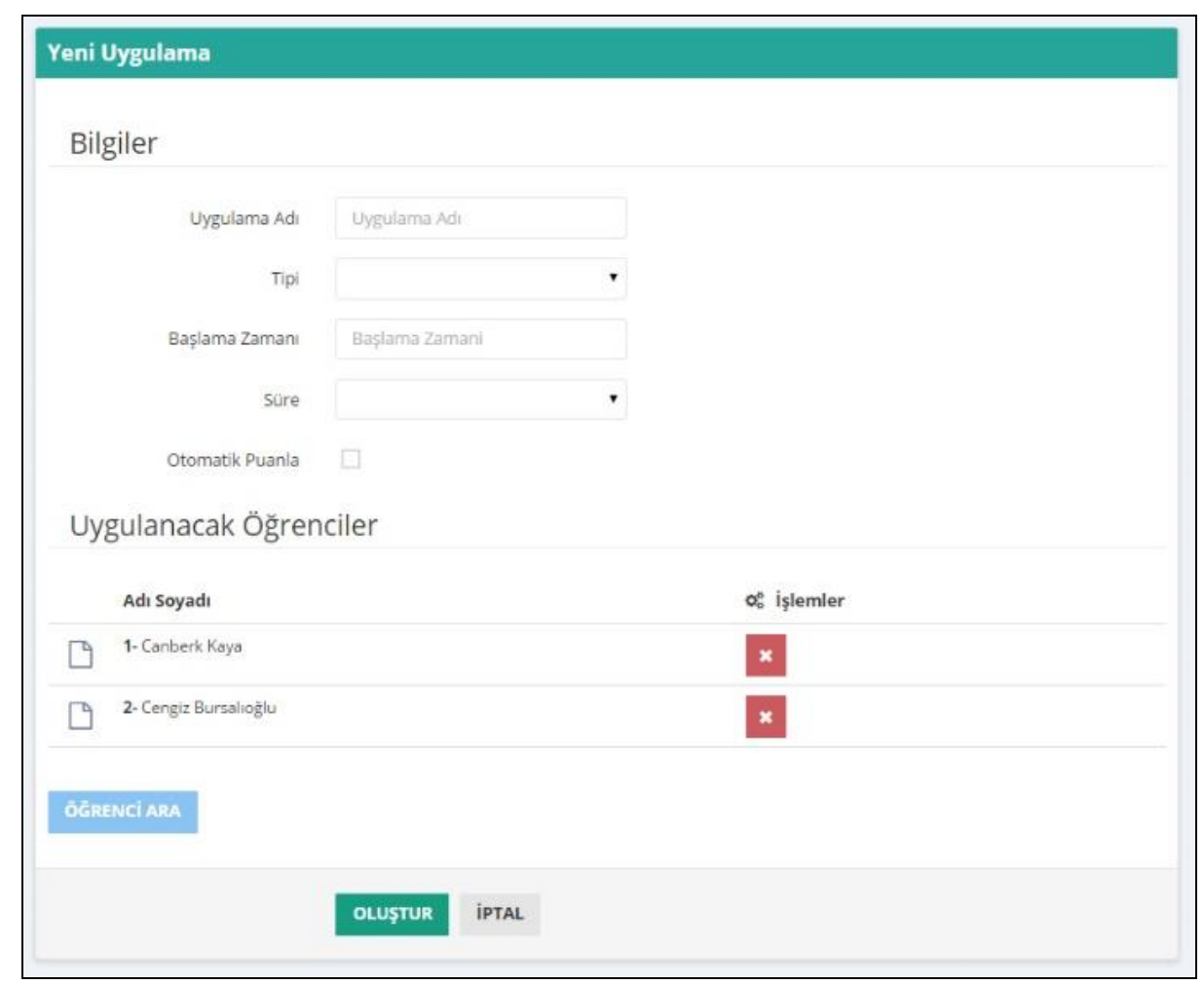

Fig 5. Assignment preparation panel

In the Table 2, we compare test objects supported by the web-based online examination system that we developed with the WizIQ and TAO applications. As we see from the table 2, our examination system offers significant advantages for the creation of tests and exams.

\begin{tabular}{|l|c|c|c|}
\hline \multicolumn{1}{|c|}{ Properties } & WizlQ & TAO & WTÇSS \\
\hline $\begin{array}{l}\text { Containing questions can be searched by category } \\
\text { and keywords }\end{array}$ & $\begin{array}{c}\text { Yes } \\
\text { (Limited) }\end{array}$ & No & Yes \\
\hline Containing questions can be selected automatically & No & No & Yes \\
\hline Re - applicability & Yes & Yes & Yes \\
\hline Re - editable & No & Yes & Yes \\
\hline Determining points value of the included questions & No & No & Yes \\
\hline
\end{tabular}

Table 2. Comparing test objects

\subsection{Realization of Application}

Students can reach the applications that assigned to him in the list on their own screen. They can follow an exam which is about to begin with the on-screen clock and notifications. Exam type applications start automatically determined time by the teacher. Before the start time, system reminds students and teachers 
by electronic mail. On start time exam content appears on the student's access. Students can follow the remaining time information from the top of the screen. After starting exam, students answer the questions individually and can switch any question (answered or unanswered) with menu in sub-section. In this section, unanswered questions will be displayed in a different color to be highlighted. Until the end of examination time, students can come back to any question and can change answers of questions. But after the examination time is over or after finishing, student cannot view or reach the content of taken exams. Fig. 6 shows the students' question screen in the web-based online examination system.

Whether the teacher marks automatic scoring of the results option before the starting exam, at the end of the examination time in the system, all students can access the scores of examination and view the questions and the correct answers. When a teacher didn't mark automatic scoring, he/she should start scoring manually at the end of the examination time.

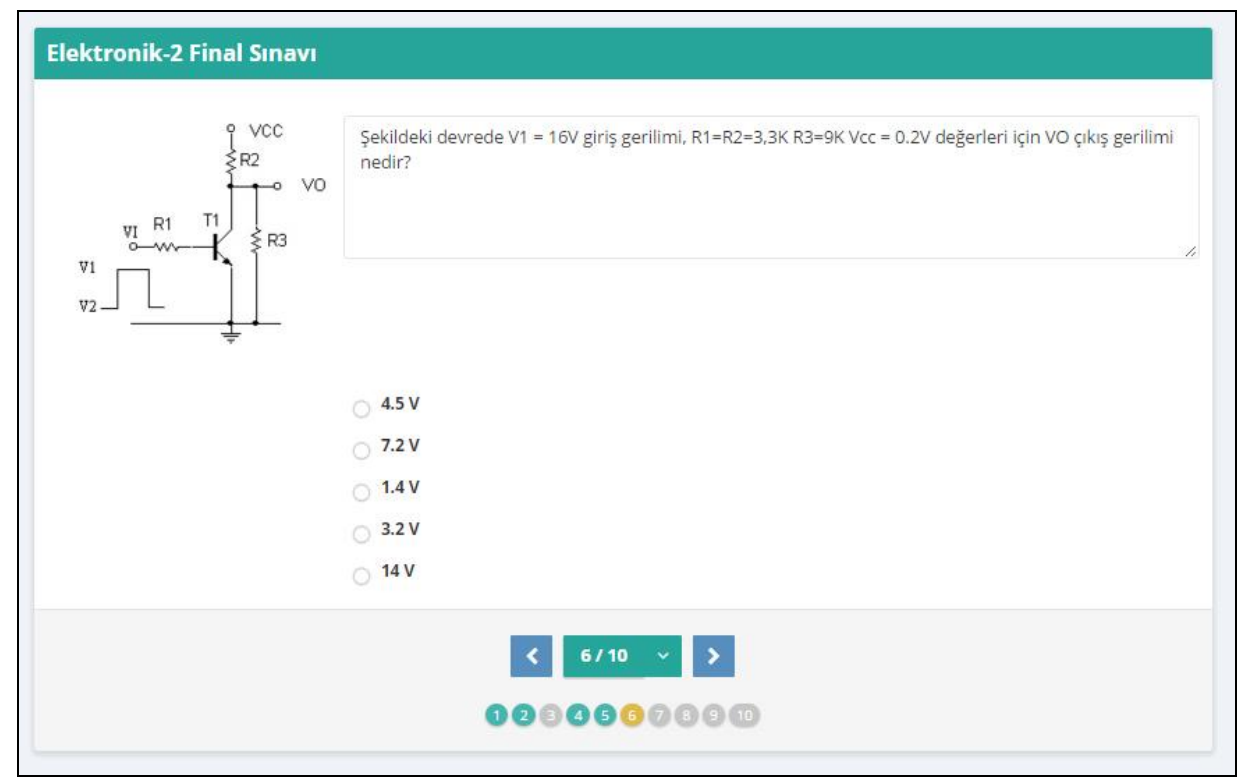

Fig 6. Student exam panel

If there are open-answered questions in the examination questions, automatic scoring option cannot be selected. After scoring the questions with open answer, other type questions are scored automatically.

Unlike the application in the examination type, in short type examination, only starting and finishing of exams are made manually by teacher. There is not time limitation in the tests. Students answer the questions of test that assigned to them at any time and after finishing the test, they can reach information about wrong and correct answers. Fig.7 shows the student's assignment list.

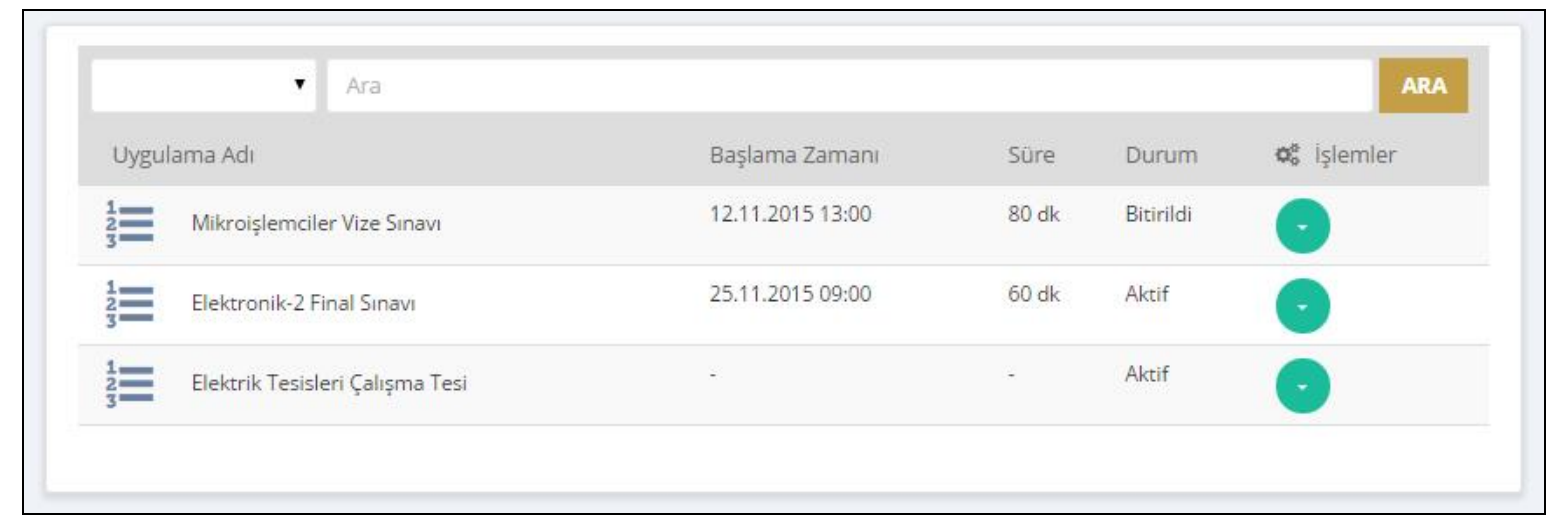

Fig 7. The list of assignment

\subsection{Examination Data}

In made applications in the system, all answers given by the students to all exams, quizzes and tests is kept in the relational database. The mean scores on the exam, the number of students who succeed and/or failed in the exam, reports related to success of the answers to specific questions can be created and displayed 
with these resulting raw data $[6,2]$. Teachers can reach to report related with their applications on the application details screen. While admin users can reach the reports which made of courses that they have authorization, master user can access the entire reports.

\section{CONCLUSION}

In this paper, we developed a web-based online examination system with multimedia support, a user-friendly interface and updatable database structure that applicable over a secure network and the internet, hold the data safely. This proposed system allows updating the questions in an easy way, reuse of the questions which used in previous exams, the creation of a large question pool. In this examination system, more effective assessment can be made by performing the data analysis and enhancing security. Furthermore, extensive digital question pool of system which developed as long as it used also simplifies the online exams that will be done in the future. Multimedia supported questions (video, audio, pictures) that can be added to the question pool by teachers allow the assessment of the students in different ways. Developed online examination environment in this study supports questions with multiple choice, true / false answer, multiple correct answers. The number of questions in examinations are not constant, it is defined by teachers in order to their requirements. While impossibility of returning to an answered question and changing answer causes problems in inflexible online examination systems, students can pass from a question to another one which they want during the examination in developed system.

In the future works, we would work on the creation of the more efficient, improved and secure system, to measure the students' knowledge and creativity on the more effective way by adding web-based interactive question types and to improve security by using biometric recognition technologies and fingerprint recognition technology (PITT).

\section{REFERENCE LIST}

[1] Aimin, W., \& Jipeng, W. (2009, May). Design and implementation of web-based intelligent examination system. WRI World Congress on Software Engineering, 2009 (Vol. 3, pp. 195-199). doi: 10.1109/WCSE.2009.77.

[2] Akin O., "Web-based Examination Systems", Master Thesis, Sakarya University, Computer \& Information Engineering, Sakarya, June, 2007:29.

[3] Crisp, V., \& Ward, C. (2008). The development of a formative scenario-based computer assisted assessment tool in psychology for teachers:The PePCAA project.Computers \& Education, 50(4),15091526.

[4] Gul E., Dogan C. (2011), "Is Online Assessment reliable?", $5^{\text {th }}$ International Computer \& Instructional Technologies Syposium, Elazig, September, 2011.

[5] Hang, B, "The design and implementation of on-line examination system", Proceedings of the International Symposium on Computer Science and Society (ISCCS), 2011 (pp. 227-230). doi: 10.1109/ISCCS.2011.68.

[6] Jin, X., \& Ma, Y. (2008). Design and implementation to intelligent examination system for e-business application operation. Knowledge-Based Intelligent Information and Engineering Systems (pp. 318323). Berlin, Germany: Springer doi: 10.1007/978-3- 540-85565-1_40.

[7] Joi L. Moore , Camille Dickson-Deane, Krista Galyen, "e-Learning, online learning, and distance learning environments: Are they the same?", Internet and Higher Education 14 (2011) 129-135, 2010.

[8] Karal, H. \& Cebi, A. (2011). The evaluation of student performance via the fuzzy logic approach, IETC, Proceedings Book Vol 2, 1445-1451.

[9] Mohammad Sarrayrih, Mohammed Ilyas,"Challenges of Online Exam, Performances and problems for Online University Exam", IJCSI International Journal of Computer Science Issues, Vol. 10, Issue 1, No 1, January 2013 ISSN (Print): 1694-0784 | ISSN (Online): 1694-0814 www.IJCSI.org.

[10] Mustafa Yagci , Huseyin Ekiz, Shelahattin Gelbal, "Designing and Applying a New Online Examination Model", Journal of Kirshehir Education Faculty (KEFAD), Ahi Evran University, Volume 16, number 1, Aprel 2015, pages 269-288.

[11] Mustafa Yagci, Menderes Ural, "Designing and Implementing an Adaptive Online Examination System", 5th World Conference on Educational Sciences, Volume 116, 21 February 2014, Pages 3079-3083.

[12] Mustakerov, I., \& Borissova, D. (2011). A conceptual approach for development of educational Web- 
based e-testing system. Expert Systems with Applications, 38(11), 14060-14064.

[13] Sampson D., P.Goodyear. "Next generation e-learning system: Intelligent applications and smart design.",Education Technology and Society, 2006, 9(3):1-2.

[14] Shan Wei-feng, Huang Meng, Li Jun, "An online examination system supporting user-defined question type", Education Technology and Computer (ICETC), 2010,2nd International Conference on (Volume:1), 22-24 June 2010, V1-109 - V1-112.

[15] Shen, R., Tang, Y., \& Zhang, T. (2001). The intelligent assessment system in web-based distance learning education. Proceedings of the Frontiers in Education Conference (Vol. 1, pp. TIF-7). doi: 10.1109/FIE.2001.963855.

[16] Stephens R., Plew R., (2003), 24 Saatte Veritabanlari, Alfa Yayinlari, Istanbul: 4 - 429 - 975.

[17] Tugrul Tashci , Zekeriya Parlak, Alpaslan Kibar, Nevzat Tashbash and H. İbrahim Cebeci,"A Novel Agent-Supported Academic Online Examination System", Educational Technology \& Society, 17(1),154-168, 2014.

[18] Welling L., Thomson L. (2004), PHP ve MySQL, Alfa Yayinlari, Istanbul: 2 - 117 - 297 -975

[19] Xing-dong Yang, "The Research on Online Examination System of PE Theory Courses",Proceedings of the 2012 International Conference of Modern Computer Science and Applications, Volume 191 of the series Advances in Intelligent Systems and Computing pp 357-362.

[20] Yagci, M., Ekiz, H., Gelbal, S. "Effects of Online Examination System on Academic Achievement of Students", 5. International Computer and Study Technology Symposium, Elazig: Firat University, p. 185-190, 2011.

[21] Zhang, L., Zhuang, Y. T., Yuan, Z. M., \& Zhan, G. H. (2006). A web-based examination and evaluation system for computer education. Proceedings of the Sixth International Conference on Advanced Learning Technologies (pp. 120-124). doi: 10.1109/ICALT.2006.1652383. 